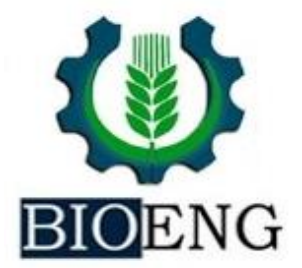

\title{
DESENVOLVIMENTO DE TÉCNICA DE CLONAGEM DE PLANTAS POR PROCESSO DE ESTAQUIAS IN VITRO EMPREGANDO VITAMINA B1 COMO REGULADOR DE ENRAIZAMENTO
}

\author{
UFSCar - Universidade Federal de São Carlos, Centro de Ciências Agrárias, Campus de
} Araras, SP, Brasil.

Article history: Received 18 September 2018; Received in revised form 18 November 2018; Accepted 21 November 2018; Available online 19 December 2018.

\section{RESUMO}

Este trabalho visou desenvolver uma metodologia de clonagem combinando as técnicas de estaquia e em in vitro realizada em laboratório. A técnica por estaquia utiliza elevadas concentrações de substâncias reguladoras de enraizamento e dificulta o acompanhamento visual do desenvolvimento radicular por ser inserida diretamente no solo. A técnica in vitro demanda laboratórios e operações sofisticadas. Ambas as tecnologias disponíveis são de elevado custo. Assim, objetivou-se estudar uma nova metodologia que não demandasse laboratórios sofisticados nem custos elevados e que permitisse um bom acompanhamento visual dos estudos. Para reduzir custos com insumos foi empregado vitamina B1 (Cloridrato de Tiamina) como substância reguladora de enraizamento misturada a uma solução de macro e micronutrientes em concentrações otimizadas para o desenvolvimento das plantas. Sobre a solução de nutrientes foram adicionados $0,8 \%$ de Agar para formação de uma camada de nutrientes em gel onde foram acondicionadas estaquias da espécie Callianthe striata (Dicks. ex Lindl.) Donnel (Malvaceae) para realização dos experimentos. Esta espécie é conhecida como lanterna chinesa e é muito utilizada em jardinagem. Após 30 dias de clonagem observou-se germinação em torno de 40 a $50 \%$ das estaquias com aparecimento de folhas e raízes. As plantas com melhor desenvolvimento foram transferidas para vasos com substratos nutrientes. Decorridos dois anos pôde-se observar plantas sadias com produção de flores similares à matriz. Esta nova técnica de clonagem apresenta custo muito baixo, sem exigir laboratórios sofisticado e é de fácil operação.

Palavras-chave: clonagem de planta, estaquia in vitro, vitamina B1.

\section{DEVELOPMENT OF PLANT CLONING TECHNIQUE BY IN VITRO STARTING PROCESS USING VITAMIN B1 AS A ROOTING REGULATOR}

\begin{abstract}
This work aimed to develop a cloning methodology combining cutting and in vitro reproduction techniques performed in laboratories. The cutting technique uses high concentrations of rooting regulator substances and it is difficult to visualize root development because it is inserted directly into the soil. In vitro technique demands sophisticated laboratory infrastructure and operations. Because of that, both technologies are quite expensive. Thus, the objective was to study a new methodology that did not require sophisticated laboratory infrastructure or elevated costs, and allowed great visual monitoring of the studies and had a good reproduction effectiveness. For reduce input costs, vitamin B1
\end{abstract}

*ronaldopelegrini@gmail.com 
(Thiamine Hydrochloride) was used as a regulator substance and it was mixed with a solution of macro and micronutrients at concentrations optimized for the plant development. On the culture substrate, was added $0.8 \%$ of Agar to form a layer of nutrients in gel where were added stains of the species Callianthe striata (Dicks. ex Lindl.) Donnel (Malvaceae) were conditioned for the accomplishment of the experiments. After 30 days of cloning germination, was observed around 40 to $50 \%$ of the stains with the appearance of leaves and roots. The plants with better root and leaf development were transferred to pots with nutrient substrates in order to evaluate the evolution of reproduction. After two years, it was possible to observe healthy plants with similar flowering rates to the matrix. This new cloning technique is deemed low cost, without requiring sophisticated laboratory infrastructure and is easy to operate.

Keywords: plants cloning, cutting technique in vitro, vitamin B1.

\section{INTRODUÇÃO}

A clonagem significa uma réplica de genes ou de células obtidas através de algumas técnicas de duplicação. Os indivíduos que resultam da clonagem têm as mesmas características genéticas do original e são chamados de clone (Ambrosano et al., 2012).

Quando se fala em clonar plantas na verdade significa realizar uma reprodução sem o plantio de sementes, gerando espécies geneticamente idênticas, isto acontece porque nas plantas, a maioria das células funciona como uma célula tronco, sendo capaz de se reproduzir e gerar uma nova planta com genética idêntica à original (Yamasaki, 2015).

A ideia de cultivar células isoladas de plantas surgiu em 1902 com Gottlieb Haberlandt, um ilustre botânico alemão, como uma estratégia capaz de materializar os conceitos embutidos na teoria celular proposta por Schwann e Shleider por volta de 1839. Esta teoria conceituava a célula (vegetal e animal) como a menor unidade biológica, autônoma, e capaz, em princípio, de originar um organismo inteiro. Assim, ela afirmava que a célula madura do corpo de um organismo pluricelular (célula somática) manteria seu material genético em condições de originar um indivíduo idêntico à matriz doadora, comportando-se, desta forma, como se fosse uma célula-ovo ou zigoto. A questão era descobrir como fazer uma célula madura e especializada (diferenciada), programada para a realização de funções específicas, voltar ao estágio embrionário. A tarefa não era pequena para a época de Haberlandt e continua desafiadora e mal compreendida para a ciência ainda hoje (KERBAUY, 1997).

Haberlandt, todavia, legou às gerações seguintes de pesquisadores algo muito importante para o avanço do conhecimento científico, ou seja, princípios bem fundamentados e procedimentos técnico-teóricos a serem seguidos, tendo alguns destes últimos se mostrado mais tarde quase que como verdadeiras "premonições" (KERBAUY, 1997).

\section{A clonagem por estaquias}

A aplicação de reguladores de crescimento em estaquias vem sendo realizada desde o início a implantação da técnica, sendo reconhecida como uma prática indispensável para a melhoria do enraizamento, tanto em termos de percentuais quanto de velocidade para formação de raízes e vigor do sistema radicular formado (WENDLING, 2014; MENDONÇA et al., 2018).

Os hormônios são substâncias naturais produzidas pela própria planta, e reguladores de crescimento são produtos sintéticos aplicados nas plantas ou em partes dela, com ação similar aos hormônios naturais (WENDLING, 2014).

Inúmeros estudos foram desenvolvidos visando à definição dos tipos de reguladores de crescimento mais 
indicados, concentrações e formas de aplicação adequadas ao processo de clonagem via estaquia, no qual, em geral, $6000 \mathrm{mg} . \mathrm{L}^{-1}$ do ácido indolbutírico (AIB) têm sido os mais recomendados, bem como a aplicação via pó em vista das maiores facilidades operacionais. No entanto, dependendo da idade da planta matriz a ser clonada, podem ocorrer variações na concentração recomendada (WENDLING, 2014).

\section{A clonagem in vitro}

Uma outra forma de clonagem de plantas é realizada em laboratório por meio do desenvolvimento de um meio de cultivo adequado. Esta técnica é conhecida como cultivo in vitro.

O cultivo in vitro é uma ferramenta biotecnológica em que células, tecidos, órgãos e/ou plantas inteiras são cultivadas de forma asséptica em um meio nutritivo, sob condições controladas de densidade de fluxo de fótons, fotoperíodo e temperatura. Todo o procedimento deve ocorrer em laboratório específico, utilizando um sistema totalmente asséptico, livre de microrganismos contaminantes como fungos e bactérias (SILVA \& FERREIRA 2016).

O ideal é que o espaço físico do laboratório seja dividido em áreas isoladas, de forma a separar a execução de algumas atividades, criando, assim, um fluxo de trabalho e reduzindo a ocorrência de contaminações. Equipamentos e outros materiais também devem ser organizados de acordo com a atividade a que estão relacionados e de maneira que fiquem facilmente acessíveis a quem for utilizálos. Basicamente, os ambientes devem ser divididos em: sala de limpeza das vidrarias e esterilização; sala de preparo de meio de cultura; sala de inoculação para manipulação asséptica do material vegetal; sala de crescimento ou incubação que mantem as condições controladas (SILVA \& FERREIRA 2016).

No caso do meio de cultivo in vitro utilizam-se os nutrientes necessários para o crescimento e desenvolvimento dos tecidos vegetais cultivados e também hormônios ou reguladores de crescimento, tais como, ácido indolacético (AIA), ácido indolbutírico (AIB), ácido naftaleno acético (ANA), 2,4-diclofenoxiacétioco (2,4-D) e Picloram (SILVA \& FERREIRA 2016).

\section{O uso de Vitaminas}

Vitaminas são substâncias orgânicas indispensáveis à manutenção das funções metabólicas do organismo. A maior parte das vitaminas atua como coenzima; isto explica seu papel essencial nos processos biológicos (Barthus, et al., 2007). Em pesquisas destinadas a reprodução de plantas as vitaminas vêm sendo empregadas no meio de cultivo com a função de colaborar no estimulo do enraizamento (Hoffmann, et al., 2001; Carvalho, et al., 2011; Ribeiro, et al., 2011; Ferreira, et al., 2011). Estudos realizados por Ribas, et al., (2002), com complexo vitamínico B5, sugerem um aumento no número de brotos e que concentrações elevadas de vitaminas no meio de cultura, intensifica a formação de gemas.

Neste estudo, empregou-se vitamina B1 (Cloridrato de Tiamina) como substância reguladora do enraizamento. A escolha desse tipo de vitamina foi em função do baixo custo e disponibilidade no mercado.

\section{Justificativas}

Os procedimentos descritos para clonagem por estaquias e clonagem in vitro encarecem muito a aplicação das tecnologias. As substâncias reguladoras de crescimento, tradicionalmente utilizadas, têm um custo muito elevado e são empregadas em grandes quantidades. As técnicas de clonagem in vitro demandam laboratórios sofisticados e são, portanto, de alto custo.

Este trabalho propõe novos procedimentos de clonagem combinando as técnicas por estaquia e em in vitro, buscando realizar os processos em laboratório comum. Utilizou-se vitamina B1 como regulador de enraizamento misturado a um meio de cultivo contendo macro e micro nutrientes, com adição de 
alíquotas de água sanitária para minimizar o desenvolvimento de patógenos. Desta forma, pôde-se reduzir consideravelmente os custos e os procedimentos com a

\section{METODOLOGIAS}

O desenvolvimento desta técnica de clonagem partiu dos procedimentos da produção do meio de cultivo realizado por Pelegrini et al., (2014), para ensaios ecotoxicológicos que usavam sementes como organismos testes. A escolha deste meio de cultivo foi em razão do rígido controle dos valores de $\mathrm{pH}$ por meio do uso de uma solução tampão que também continha nutrientes. Neste trabalho, clonagem de vegetais. Assim, a técnica foi denominada por: clonagem por estaquia in vitro.

Tabela 1. Concentrações de macro e micronutrientes para elaboração do meio de cultivo para clonagens de plantas utilizando solução Tampão de Fosfato monobásico $\left(\mathrm{KH}_{2} \mathrm{PO}_{4}\right)$ e bibásico $\left(\mathrm{K}_{2} \mathrm{HPO}_{4}\right)$ de Potássio.

\begin{tabular}{|c|c|c|c|c|c|c|c|c|}
\hline Nutrientes & $\mathbf{K}$ & $\mathbf{P}$ & $\mathbf{N}$ & $\mathbf{C a}$ & $\mathbf{M g}$ & $\mathbf{B}$ & Mo & VB1 \\
\hline mg.L $^{-1}$ & 61,00 & 41,00 & 35,00 & 30,00 & 38,00 & 0,30 & 0,06 & 400,00 \\
\hline
\end{tabular}

\section{Como produzir o meio de cultivo.}

\section{- Preparo da Solução Tampão}

Iniciou-se a produção do meio de cultivo a partir do preparo das soluções ácida $\left(\mathrm{KH}_{2} \mathrm{PO}_{4} 0,01 \mathrm{~mol} \cdot \mathrm{L}^{-1}\right)$ e básica $\left(\mathrm{K}_{2} \mathrm{HPO}_{4}\right.$ 0,01 mol. $\left.\mathrm{L}^{-1}\right)$ da solução tampão. Foi realizado uma titulação potenciométrica usando $25 \mathrm{~mL}$ da solução ácida para estabelecer os respectivos volumes da empregou-se as mesmas concentrações de macro e micronutrientes usadas nos ensaios, com o acréscimo de vitamina B1 (Cloridrato de Tiamina) para estimular o enraizamento ao invés dos tradicionais reguladores de crescimento. A Tabela 1, apresenta a média das concentrações de macro e micronutrientes otimizadas para o desenvolvimento das plântulas.

Tabela 2. Volumes das soluções ácida (A) e básica (B) para preparação de $1000 \mathrm{~mL}$ de solução Tampão nos respectivos valores de $\mathrm{pH}$.

\section{Soluções precursoras:}

A: Solução 0,01 mol. $\mathrm{L}^{-1}$ de fosfato de potássio monobásico $\left(\mathrm{KH}_{2} \mathrm{PO}_{4}\right)$

B: Solução 0,01 mol.L ${ }^{-1}$ de fosfato de potássio bibásico $\left(\mathrm{K}_{2} \mathrm{HPO}_{4}\right)$

\begin{tabular}{|c|c|c|c|}
\hline $\mathrm{pH}$ & $\begin{array}{c}\text { Volume da solução A } \\
\left(\mathrm{KH}_{2} \mathrm{PO}_{4}\right) \\
(\mathrm{mL})\end{array}$ & $\begin{array}{c}\text { Volume da solução B } \\
\left(\mathrm{K}_{2} \mathrm{HPO}_{4}\right) \\
(\mathrm{mL})\end{array}$ & $\begin{array}{c}\text { Volume da } \\
\text { solução Tampão } \\
(\mathrm{mL})\end{array}$ \\
\hline 6,0 & 896 & 104 & 1000 \\
\hline 6,5 & 713 & 287 & 1000 \\
\hline 7,0 & 418 & 582 & 1000 \\
\hline 7,5 & 172 & 828 & 1000 \\
\hline
\end{tabular}


- Cálculos das Massas de Potássio e de Fosforo na Solução Tampão

Segundo Pelegrini et al., 2014, para calcular as massas de potássio na solução tampão utiliza-se a equação 1, e para as massas de fósforo a equação 2 , onde a massa de potássio no tampão é representada por $\left(\mathbf{M}_{\mathbf{K T}}\right)$ e massa de fósforo no tampão (MPT), volume da solução ácida $\mathbf{V}_{\mathbf{A}}$ e volume da solução básica $\mathbf{V}_{\mathbf{B}}$. Empregando as equações a partir dos volumes das soluções em "mL" o resultado é expresso diretamente em "mg" (eqs. 1 e 2).

$$
\begin{aligned}
& \mathrm{M}_{\mathrm{KT}}=0,39 \mathrm{~V}_{\mathrm{A}}+0,78 \mathrm{~V}_{\mathrm{B}} \mathrm{mg} \\
& \mathrm{M}_{\mathrm{PT}}=0,39\left(\mathrm{~V}_{\mathrm{A}}+\mathrm{V}_{\mathrm{B}}\right) \mathrm{mg}
\end{aligned}
$$

A Tabela 3, apresenta as massas de potássio e de fósforo em $1000 \mathrm{~mL}$ de solução tampão nos respectivos valores de $\mathrm{pH}$ em que as soluções foram preparadas. Esses cálculos são fundamentais para determinar o volume da solução tampão que corresponde às concentrações de potássio e de fósforo indicadas na Tabela 1. No caso do potássio é necessário determinar qual o volume da solução tampão que corresponde a $61 \mathrm{mg}$ do potássio. Vale lembrar que o potássio aparece nas estruturas químicas das espécies ácida e básica em proporções diferentes, mas isto já foi considerado quando se empregou a eq.1.

Tabela 3. Cálculo das massas de potássio e de fósforo em $1000 \mathrm{~mL}$ de solução tampão para as soluções precursoras: $\mathrm{KH}_{2} \mathrm{PO}_{4} \quad 0,01$ mol. $\mathrm{L}^{-1}$ e $\mathrm{K}_{2} \mathrm{HPO}_{4} \quad 0,01 \mathrm{~mol} . \mathrm{L}^{-1}$ nos respectivos valores de $\mathrm{pH}$

\begin{tabular}{|c|c|c|}
\hline pH & $\begin{array}{c}\text { Massa total de K no } \\
\text { tampão } \\
\left(\text { mg.K.. }^{-1}\right)\end{array}$ & $\begin{array}{c}\text { Massa total de P no } \\
\text { Tampão } \\
\left(\text { mg.P.. }^{-1}\right)\end{array}$ \\
\hline 6,0 & 430,5 & 310 \\
\hline 6,5 & 502,0 & 310 \\
\hline 7,0 & 617,0 & 310 \\
\hline 7,5 & 712,9 & 310 \\
\hline
\end{tabular}

De posse dos dados da Tabela 3 pôde-se calcular, por uma regra de três simples, o volume da solução tampão que correspondeu à massa de potássio necessária para preparar a solução de nutrientes: $61 \mathrm{mg}$ (Tabela 1), e, por conseguinte, a massa de fósforo presentes no volume que se tomou para determinar a massa de potássio. A solução de nutrientes deve conter as concentrações de macro e micronutrientes indicadas na Tabela 1 , independente de seus valores de $\mathrm{pH}$.

\section{- Preparo de Outras Soluções Estoques}

As outras soluções estoques de macro e micronutrientes foram preparadas em concentração comum (mg. $\mathrm{L}^{-1}$ ou $\mu \mathrm{g} . \mathrm{L}^{-}$ $\left.{ }^{1}\right)$. Optou-se por preparar as soluções estoque em concentrações de $1000 \mathrm{mg} . \mathrm{L}^{-1}$ por uma razão muito simples: por não ser necessário calcular volumes e massas. Como a solução é $1000 \mathrm{mg} . \mathrm{L}^{-1}$, significa que, em $1000 \mathrm{~mL}$ contém $1000 \mathrm{mg}$ ou, em $10 \mathrm{~mL}$ contem $10 \mathrm{mg}$ do soluto. Basta que a solução seja preparada na concentração da espécie nutriente $\left(1000\right.$ mg.Ca.L $\mathrm{L}^{-1}$, 1000mg.Mg. $\mathrm{L}^{-1}$, etc.).

\section{- Preparo da Solução de Nutrientes}

A partir das indicações de Pelegrini et al., (2014), para as concentrações médias otimizadas de macro e micronutrientes para o desenvolvimento das plantas (Tabela 1), preparou-se um litro de solução de nutrientes nas mesmas concentrações com acréscimo de 400mg de vitamina B1 como substância reguladora de enraizamento em valor de $\mathrm{pH}$ 7,0 (Tabela 4).

Acertando a concentração de potássio (conforme indicado na Tabela 1) em $61 \mathrm{mg}$, não significa que a concentração de fosforo já foi acertada. Dependendo da escolha do valor de $\mathrm{pH}$ que se deseja 
trabalhar, a massa de fósforo pode ficar incompleta, devendo ser acrescentada a partir de outra solução que tenha fósforo na estrutura, mas não potássio. Neste trabalho, foi utilizado uma solução $\mathrm{H}_{3} \mathrm{PO}_{4}$ (1000 mg.P. $\left.L^{-1}\right)$ para completar a massa de fósforo faltante.

Tabela 4. Concentrações e volumes das soluções estoque para elaboração da solução de nutrientes. Solução tampão no valor de $\mathrm{pH} 7,0$ : Fosfato monobásico $\left(\mathrm{KH}_{2} \mathrm{PO}_{4}\right)$ e bibásico $\left(\mathrm{K}_{2} \mathrm{HPO}_{4}\right)$ de Potássio 0,01 mol.L ${ }^{-1}$. Demais soluções em mg.L ${ }^{-1}$ e $\mu \mathrm{g} . \mathrm{L}^{-1}$.

\begin{tabular}{|c|c|c|c|c|c|c|c|c|}
\hline \multicolumn{9}{|c|}{$\begin{array}{l}\text { CONCENTRAÇÕES E VOLUMES DAS SOLUÇÕES ESTOQUE PARA } \\
\text { PREPARO DA SOLUÇÃO DE NUTRIENTES EM VALOR DE pH 7,0 }\end{array}$} \\
\hline $\begin{array}{c}\text { Concentração } \\
\text { das soluções } \\
\text { Estoque }\end{array}$ & 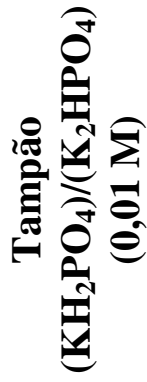 & 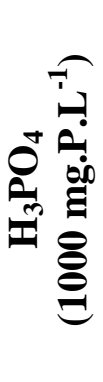 & 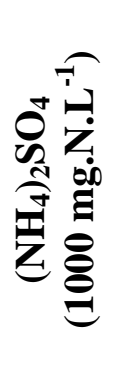 & 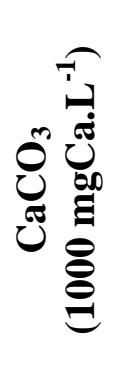 & 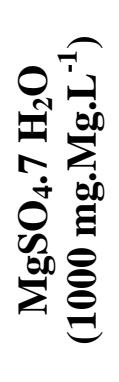 & 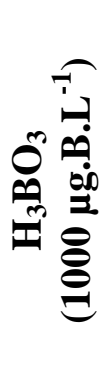 & 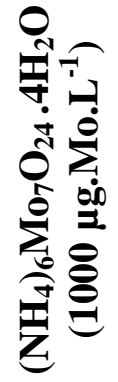 & 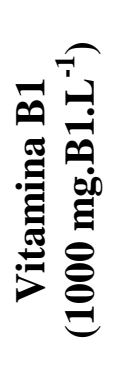 \\
\hline $\begin{array}{c}\text { Volumes } \\
\text { utilizados } \\
(\mathbf{m L})\end{array}$ & 98,9 & 2,4 & 35 & 30 & 38 & 300 & 60 & 400 \\
\hline
\end{tabular}

Após juntar todos os volumes em um balão volumétrico de $1000 \mathrm{~mL}$ o volume foi completado $1000 \mathrm{~mL}$ com água destilada. Assim, com a adição dos respectivos volumes das soluções estoque da Tabela 4, as concentrações de macro e micronutrientes são idênticas às apresentadas na Tabela 1.

Depois de preparada a solução de nutriente foi verificado se o valor de $\mathrm{pH}$ correspondia ao planejado.

- Correções dos valores de pH na Solução de Nutrientes e possíveis substâncias usadas no preparo das soluções estoque.

Com a mistura de diversas substâncias é possível observar variações dos valores de $\mathrm{pH}$ na solução de nutrientes. Neste caso, recomenda-se realizar acertos adicionando-se solução ácida (indicada: ácido cítrico ou ascórbico) quando o valor de $\mathrm{pH}$ estiver elevado, ou adicionar volumes de uma solução de base fraca (indicada: $\mathrm{Ca}(\mathrm{OH})_{2}$ ) quando o valor de $\mathrm{pH}$ estiver abaixo do planejado. Deve-se evitar a adição de sódio, pois este não é recomendado como nutriente.

Apesar das concentrações dos nutrientes estarem otimizadas, Pelegrini et al., (2014), não propuseram a otimização no limite máximo de concentração de nutrientes, uma vez que existe uma margem de segurança.

Para a solução estoque de nitrogênio indica-se empregar também soluções de ureia (1000mg.N.L $\left.\mathrm{L}^{-1}\right)$ no lugar da $\left(\mathrm{NH}_{4}\right)_{2} \mathrm{SO}_{4}$, para evitar os excessos de íons sulfatos $\left(\mathrm{SO}_{4}{ }^{\circ}\right)$. Isso porque apesar de ser macro nutriente, ele irá provocar toxicidade e poderá prejudicar o enraizamento se utilizado em excesso.

Para a solução estoque de cálcio pode-se utilizar acetato de cálcio ou o hidróxido de cálcio (1000mg.Ca.L $\left.\mathrm{L}^{-1}\right)$, mesmo que o hidróxido seja insolúvel no meio de cultivo, o cálcio ficará biodisponível e é muito importante para o desenvolvimento da planta.

Uma outra verificação importante neste estudo, foi que concentrações da vitamina B1 acima de $400 \mathrm{mg} . \mathrm{L}^{-1}$ não favoreceu o desenvolvimento do vegetal, 
por esta razão os testes foram realizados na concentração indicada.

\section{- Preparo do Meio de Cultivo}

O meio de cultivo desenvolvido por Pelegrini et al., (2014), empregava $1,7 \mathrm{~g}$ de Agar para $100 \mathrm{~mL}$ da solução de nutrientes. Nos testes de clonagem verificou-se que uma porcentagem de $0,8 \%$ favorecia mais enraizamento da planta. Após a adição de $0,8 \mathrm{~g}$ de Agar a $100 \mathrm{~mL}$ de solução de nutrientes levou-se a mistura ao aquecimento até o "início de uma fervura enérgica" agitando sempre com um bastão de vidro.

Seguindo as recomendações de Pelegrini et al., (2014), foi acrescentado duas gotas de água sanitária a cada $100 \mathrm{~mL}$ do meio de cultivo para impedir desenvolvimento de patógenos e competição de espécies indesejadas. $\mathrm{O}$ momento ideal para adicionar a água sanitária é quando o meio de cultivo ainda não se transformou em gel (temperaturas em torno de $45^{\circ} \mathrm{C}$ ), amenizando assim, a evaporação de substâncias bactericidas e fungicidas presentes na água sanitária.

Logo que o meio de cultivo recebeu as gotas de água sanitária, sob temperatura de $45^{\circ} \mathrm{C}$, misturou-se bem com o bastão de vidro, e alíquotas de $20 \mathrm{~mL}$ foram transportadas para tubos de ensaios de $50 \mathrm{~mL}$ com o meio de cultivo ainda quente. Aguardou-se o tempo de enrijecimento do Agar (sob temperatura ambiente) e posteriormente, colocou-se as estaquias das plantas a serem clonadas.

\section{- Preparo da Planta para Clonagem}

Para implementar esta tecnologia utilizou-se a planta Callianthe striata (Dicks. ex Lindl.) Donnel (Malvaceae), conhecida como lanterna chinesa. $C$. striata é uma espécie endêmica do Brasil e apresenta lâminas foliares 3-5 partidas, flores pendentes com pétalas alaranjadas com as nervuras avermelhadas e mancha basal amarela, além de estames de ápice avermelhado que se projetam além das pétalas (TAKEUCHI, 2018). Esta espécie é um arbusto bastante rústico que demanda muito sol para seu cultivo e que está bastante adaptada ao clima do Brasil (PATRO, 2018), razão pela qual optou-se por empregá-la no desenvolvimento dos estudos.

Para realizar a clonagem escolheu-se ramos com até $0,5 \mathrm{~cm}$ de largura e tamanhos de aproximadamente $20 \mathrm{~cm}$, priorizando os ramos com folhas e fazendo estaquias com cortes em diagonal na parte inferior para aumentar o contato da plântula com o meio de cultivo. As pontas excessivas das folhas grandes foram cortadas e das menores foram mantidas.

As estaquias preparadas anteriormente foram acomodadas no centro do tubo de ensaio sendo introduzidas até o fundo do meio de cultivo, e em seguida foram envolvidas com um filme de PVC vedando ao máximo os orifícios entre o tubo de ensaio e os ramos das plântulas, para minimizar a evaporação de água do meio de cultivo (Figura 1).

As amostras foram mantidas em ambiente claro sem incidência direta da luz solar por um período de 20 a 30 dias. Após este tempo avaliou-se o enraizamento e o surgimentos de novas folhas. A partir desse momento as plantas foram transportadas para vasos com substratos orgânicos ou plantadas diretamente em covas preparadas com nutrientes. 


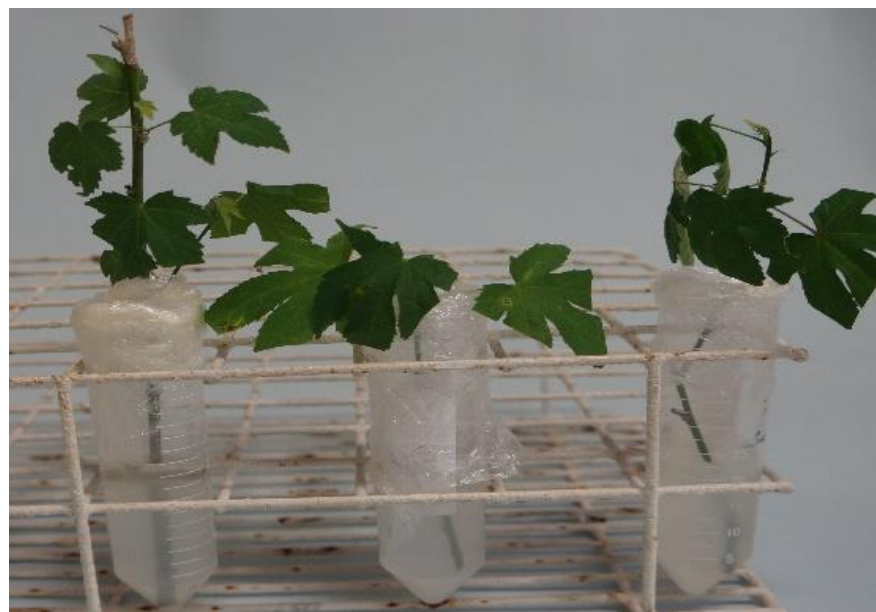

Figura 1. Fotografia das estaquias da planta Callianthe striata (Dicks. ex Lindl.) Donnel (Malvaceae), no meio de cultivo acondicionadas para clonagem.

\section{RESULTADO E DISCUSSÃO}

\section{A Clonagem vegetal}

Os ensaios de clonagem com a planta Abutilon striatum, utilizando a técnica de estaquia in vítreo, apresentou uma eficiência de reprodução em torno de 40 a $50 \%$, sendo eficiente tanto para estaquias largas como para as estreitas. O surgimento de folhas e raízes pôde ser observado a partir do $15^{\circ}$ dia de exposição ao meio de cultura. Após 30 dias as plantas apresentavam um bom desenvolvimento radicular e da parte aérea (Figura 2).

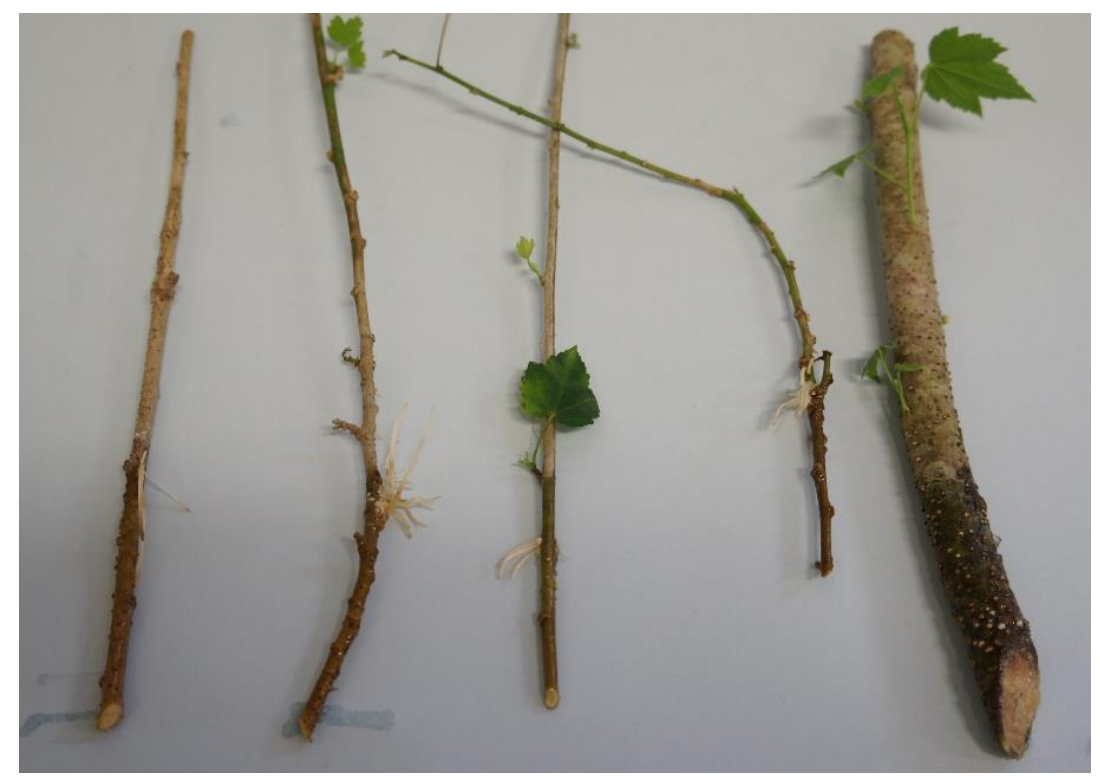

Figura 2. Fotografia das estaquias da planta Callianthe striata (Dicks. ex Lindl.) Donnel após 30 dias no meio de cultivo para reprodução.

Após o período de 30 dias de exposição no meio de cultivo, algumas estaquias que apresentavam melhor desenvolvimento foram transferidas para plantio em vasos com substratos orgânicos contendo nutrientes. Decorrido dois anos de experimento da clonagem, as plantas apresentaram desenvolvimento sadio e aparência muito similar à matriz de onde foram retiradas as estaquias para reprodução (Figura 3). 


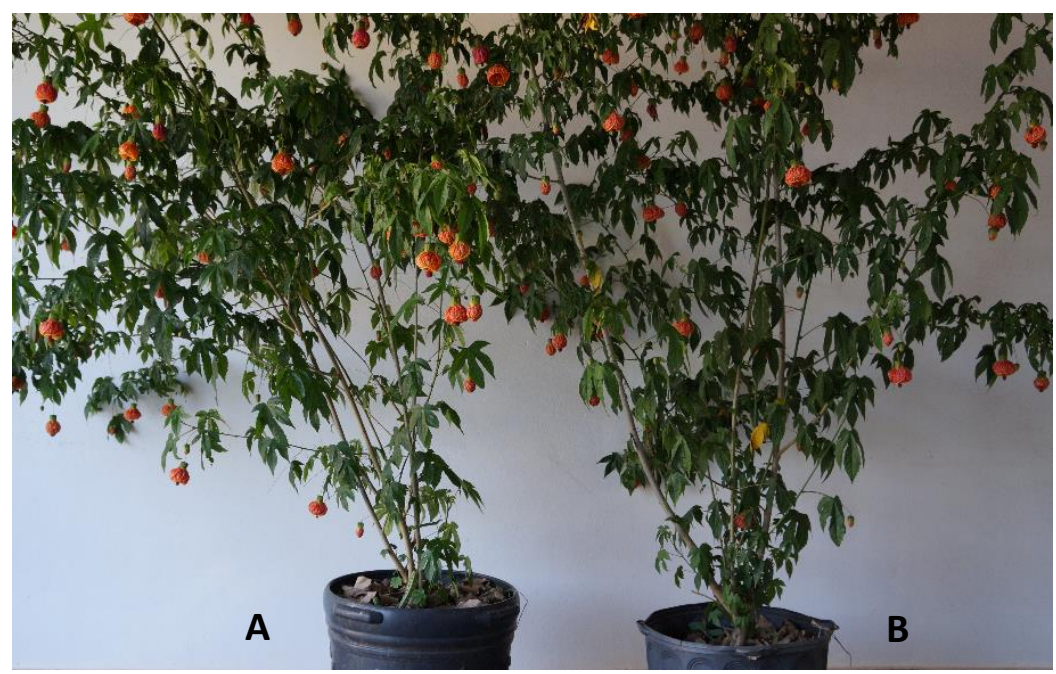

Figura 3. Fotografia comparativa da planta matriz (A) e da planta clonada (B) de Callianthe striata (Dicks. ex Lindl.) Donnel (Malvaceae), após dois anos de crescimento.

Plantas propagadas vegetativamente por meio de técnicas de clonagens, uma vez infectadas por vírus, microplasmas, bactérias e fungos endógenos, transmitem inescapavelmente estes patógenos às gerações subsequentes, provocando uma diminuição progressiva no rendimento das culturas. O cultivo de espécies com retornos abaixo do potencial genético produtivo, selecionado previamente, é inaceitável hoje em dia (KERBAUY 1997).

\section{A Eliminação de Patógenos}

A técnica de clonagem por estaquia in vitro desenvolvida neste estudo mostrou que procedimentos simples como adicionar duas gotas de água sanitária fazem toda diferença na produção de novas espécies e também no desenvolvimento do meio de cultivo (Figura 4).

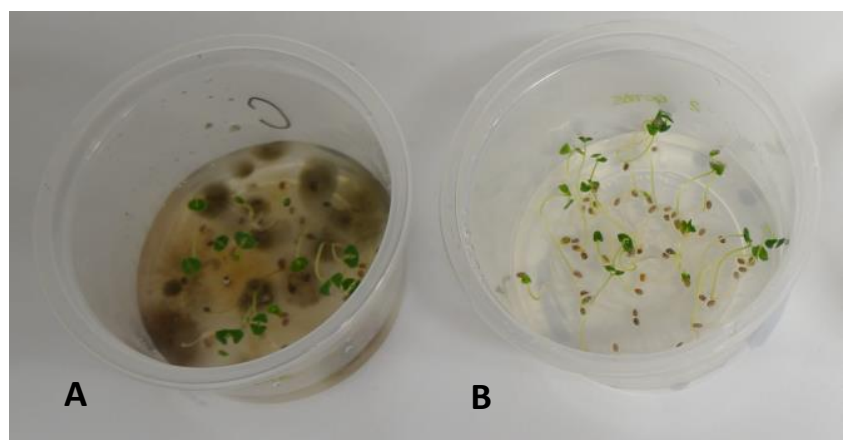

Figura 4. Fotografia comparativa do meio de cultivo sem adição de agua sanitária (A), e com adição de duas gotas de água sanitária (B), para 100mL de meio de cultivo exposto em ambiente contaminado com fungos.

Avaliações comparativas realizadas com plantas de um mesmo cultivar infectadas com vírus, mostraram que, aquelas livres destes patógenos, via cultura de ápices meristemáticos, eram duas vezes mais produtivas. $\mathrm{O}$ fato de uma planta ter sido limpa de vírus, ou de outro patógeno em laboratório, não confere a ela nenhuma imunidade a novas infecções. Porém, torna-se condição importante que técnicas de reprodução atendam a uma produção contínua de plantas livres de patógenos (KERBAUY 1997). 


\section{CONCLUSÕES}

A grande vantagem de usar a clonagem de plantas por meio de estaquias in vitro é que se pode empregar um meio de cultivo em gel que facilita o enraizamento das plantas, favorece uma rápida adsorção dos nutrientes e $\mathrm{o}$ crescimento acelerado. Além disso, facilita o acompanhamento dos estudos pela fácil visualização.

A técnica desenvolvida neste estudo, com uso da vitamina B1 como regulador de enraizamento, sem empregar laboratórios sofisticados, pode reduzir enormemente os custos para reprodução de plantas de interesse.

Como é uma técnica simples que pode ser empregada até mesmo em laboratório de ensino, torna-se também uma grande ferramenta pedagógica para aulas práticas de diversas disciplinas. Os conceitos de concentração de soluções, solução Tampão e cálculos químicos podem ser explorados de forma bem

\section{AGRADECIMENTOS}

Esta pesquisa foi implementada a partir do Programa de Educação Tutorial PET Licenciatura em Química (PET - Mec / SESu / DIFES), Centro de Ciências Agrárias (CCA) - Universidade Federal de

\section{REFERÊNCIAS BIBLIOGRÁFICAS}

AMBROSANO, M. N.; JUSTINO, M. M.; CARDOZO, L. T.; BOCATTO, S.; COSTA, M. F. Aspectos gerais da clonagem vegetal - com ênfase na cana-deaçúcar. $\mathbf{1 0}^{\circ}$ Simpósio de Ensino de Graduação. UNIMEP 2012.

BARTHUS, R. C.; MAZO, L. H.; POPPI, R. J. Aplicação de métodos de calibração multivariada para a determinação simultânea de riboflavina (VB2), tiamina (VB1), piridoxina (VB6) e nicotinamida (VPP). Quimica Nova, v. 30, n.7, 2007.

CANÇADO, G. M. A.; RIBEIRO, A. P.; FREITAS, G. F.; SÁ, M. E. L.; SILVA, H. E.; PASQUAL, M.; VAL, A. D. aplicada, com objetivos bem definidos para uso prático.

Diversos reagentes podem ser empregados para montar a tabela de nutrientes apresentada neste trabalho, inclusive outras vitaminas podem ser utilizadas como substâncias reguladoras de enraizamento, facilitando assim, a aquisição de compostos químicos de melhor custo e ampliando as possibilidades de aplicação da técnica.

Estudos estatísticos podem ser realizados visando pesquisas com foco na reprodutividade do método e ao uso da técnica em grande escala.

Para uso desta tecnologia na agricultura, o que sempre está em "jogo" é o menor custo e a facilidade de operação. Este estudo visou responder a estas necessidades e a metodologia deste artigo foi preparada para ser utilizada como um roteiro para a produção do meio de cultivo e para aplicação da técnica.

São Carlos (UFSCar). Os autores agradecem o suporte técnico e as bolsas cedidas pela CAPES por meio do Programa PET.

B.; NUNES, C. F. Cultivo de plantas in vitro e suas aplicações. Informe Agropecuário, v. 30, p. 64-74, 2009.

CARVALHO, D. C.; SILVA, A. L. L.; TANNO, G. N.; PURCINO, M.; BIASI, L. A. Organogênese a Partir de Segmentos Foliares e Internodais de Videira cv. Merlot. Ciênc. Agrotec. v.35, n.1, 2011.

FERREIRA, J. P.; SCHMILDT, E. R.; AMARAL, J. A. T.; SCHMILDT, O.; NASCIIMENTO, A. L.; Enraizamento in vitro de clones de mamoeiro Tainung 01 . Ver. Ciênc. Agron. v. 42, n. 2, 2011.

HOFFMANN, A.; PASQUAL, M.; CHALFUN, N. N. J.; VIEIRA, S. S. N. 
Substratos na indução e desenvolvimento in vitro de raízes em dois porta-enxertos de macieira. Pesq. Agropec. Bras. v.36, n. $11,2001$.

KERBAUY, G. B. Clonagem de Plantas In Vitro: Uma Realidade. Biotecnologia Ciência \& Desenvolvimento. v.1, p. 3033, 1997.

MENDONÇA, L. P.; BATISTA, J. N.; MAGALHÂES, W. B.; FERREIRA, J. P.; BUCHER, C. A. Ácido-indol-3-butirico e época de coleta influenciando no enraizamento de Odontonema strictum (Nees) O. Kuntze. Brazilian Journal of Biosystems Engineering v. 12 n. 2, p. 176-184, 2018.

PATRO, R. Jardim de Vasos. 1. ed. Curitiba, Paraná, 2018.

PELEGRINI, R. P.; MEDINA, A. F.; MENDES, F; MOLENA, J. C.; GREVE, L. F.; SALMAZO, L. G. S.; MILANI, P. A.; ANDRADE, P. G.; TOGNOLI, R. B. Metodología de evaluación ecotoxicológica empleando germinación de semillas en gel nutriente como medio de cultura. Rev. Ambient. Água. v.9 n.2, p. 359-372, 2014.
RIBAS, A. F.; DENIS, F.; QUOIRIN, M.; AYUB, R. A. Misturas vitamínicas na regeneração do maracujazeiro amarelo (passiflora eddulis $f$. flavicarpa deg.). Cienc. Rural. v. 32, n. 2, 2002.

RIBEIRO, L. M.; NEVES, S. C.; SILVA, P. O.; ANDRADE, I. G. Germinação de embriões zigóticos e desenvolvimento in vitro de coquinho-azedo. Rev. Ceres (Impr.). v. 58, n. 2, 2011.

SILVA, M. M. A.; FERREIRA, L. T. Cultivo in vitro de plantas $\mathrm{e}$ suas aplicações em cactáceas. Instituto Nacional do Semiárido. 1. ed. Campina Grande, Paraíba, 2016.

TAKEUCHI, C. Callianthe in Flora do Brasil 2020 em construção. Jardim Botânico do Rio de Janeiro.Disponível em: <http://floradobrasil.jbrj.gov.br/reflora/flor adobrasil/FB134862>. Acesso em: 18 Set. 2018

WENDLING, I.. Hormônios e reguladores de crescimento: realidades e mitos na clonagem de eucalipto. Revista Opiniões, v. 10, n. 34, p. 32-34, 2014.

YAMASAKI, G. O que é clonagem de plantas? Revista Cultivando. 2015. 